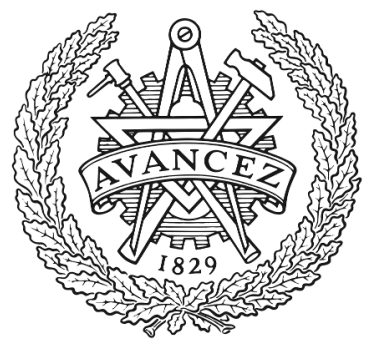

CHALMERS

UNIVERSITY OF TECHNOLOGY

\title{
Microporous Humins Synthesized in Concentrated Sulfuric Acid Using 5-Hydroxymethyl Furfural
}

Downloaded from: https://research.chalmers.se, 2023-04-26 15:25 UTC

Citation for the original published paper (version of record):

Bjornerback, F., Bernin, D., Hedin, N. (2018). Microporous Humins Synthesized in Concentrated Sulfuric Acid Using 5-Hydroxymethyl Furfural. ACS OMEGA, 3(8): 8537-8545. http://dx.doi.org/10.1021/acsomega.8b01274

N.B. When citing this work, cite the original published paper. 


\title{
Microporous Humins Synthesized in Concentrated Sulfuric Acid Using 5-Hydroxymethyl Furfural
}

\author{
Fredrik Björnerbäck, Diana Bernin, ${ }^{\dagger}{ }^{\dagger}$ and Niklas Hedin*(i) \\ Department of Materials and Environmental Chemistry, Arrhenius Laboratory, Stockholm University, SE-106 91 Stockholm, \\ Sweden
}

Supporting Information

ABSTRACT: A new class of highly porous organic sorbents called microporous humins is presented. These microporous humins are derived from sustainable and industrially abundant resources, have high heat of $\mathrm{CO}_{2}$ sorption, and could potentially be useful for the separation of carbon dioxide from gas mixtures. Their synthesis involves the polymerization of 5-hydroxymethyl furfural (HMF) in concentrated sulfuric acid and treatment with diethyl ether and heat. In particular, the porosities were tuned by the heat treatment. HMF is a potential platform chemical from biorefineries and a common intermediate in carbohydrate chemistry. A high uptake of $\mathrm{CO}_{2}$ (up to $5.27 \mathrm{mmol} / \mathrm{g}$ at $0{ }^{\circ} \mathrm{C}$ and $1 \mathrm{bar}$ ) and high $\mathrm{CO}_{2}$-over- $\mathrm{N}_{2}$ and $\mathrm{CO}_{2}$-over- $\mathrm{CH}_{4}$ selectivities were observed. The microporous humins were aromatic and structurally amorphous, which was shown in a multipronged approach using ${ }^{13} \mathrm{C}$ nuclear magnetic resonance and Fourier transform infrared spectroscopies, elemental analysis, and wide-angle X-ray scattering.

\section{INTRODUCTION}

The purpose of this study was to design a new class of organic microporous sorbents for $\mathrm{CO}_{2}$ removal processes, using only industrially abundant and sustainable resources. As of today, many microporous sorbents are derived from petroleum products or include scarce elements. Consequently, efforts are being made to synthesize sorbents through more sustainable or renewable means. ${ }^{1-3}$ It is established that carbon-rich materials can be synthesized using platform molecules of biorefineries. ${ }^{4}$ 5-Hydroxymethylfurfural (HMF) is such a molecule, ${ }^{5,6}$ which could also be used in fuel additives, as a monomer, and in the synthesis of other chemical derivatives. $^{5-7}$

When sugars or biomass are converted to HMF and levulinic and formic acids, solid side products often form. These side products are called humins. ${ }^{4,8}$ They have polymeric structures and their mechanism of formation has been studied in detail. ${ }^{8}$ They have been related to the hydrochars or biocarbons that precipitate during hydrothermal carbonization (HTC) processes, in which HMF has been shown to be an intermediate reaction product. ${ }^{9}$ The use of humins is thought to be limited to the generation of heat or as soil enhancers. ${ }^{8}$ However, because of the complex, diverse, and relatively unknown structure $^{8}$ of humins, we see large potential in using them in material applications. For instance, humin-containing foams have been prepared. ${ }^{10}$

The reactions of sulfuric acid $\left(\mathrm{H}_{2} \mathrm{SO}_{4}\right)$ with sugars have been studied for decades, and it is well established that humins form in such reactions. ${ }^{11,12}$ Another documented use of $\mathrm{H}_{2} \mathrm{SO}_{4}$ is as an activation agent in the production of activated carbons from biomass. ${ }^{13}$ Although there are variations to the procedure, typically, biomass is impregnated with $\mathrm{H}_{2} \mathrm{SO}_{4}$ and subsequently heated in a $\mathrm{N}_{2}$ atmosphere. Mechanistically, $\mathrm{H}_{2} \mathrm{SO}_{4}$ has been proposed to act as a dehydration catalyst during such activation. ${ }^{14} \mathrm{H}_{2} \mathrm{SO}_{4}$ can act as an acid catalyst during synthesis of carbon-based materials using silica templates. Hard templating of carbons using silica templates involves multiple steps and high temperatures and the carbons can have surface areas up to $2200 \mathrm{~m}^{2} / \mathrm{g}$. ${ }^{15}$ Carbon films have also been produced from sucrose and $\mathrm{H}_{2} \mathrm{SO}_{4}$ using polystyrene spheres as templates. ${ }^{16} \mathrm{H}_{2} \mathrm{SO}_{4}$ has also been used as a reagent in $\mathrm{HTC}^{17}$ of biomass and molecules and to produce sulfurdoped carbon dots from waste frying oil. ${ }^{18}$

As HMF could be a future platform chemical and is a common intermediate in carbohydrate chemistry, the objective of this study was to derive highly porous humins from it. We synthesized microporous humins with large surface areas and high levels of $\mathrm{CO}_{2}$ uptake from HMF in conc. $\mathrm{H}_{2} \mathrm{SO}_{4}$.

\section{RESULTS AND DISCUSSION}

Microporous Humins from HMF. Microporous humins were synthesized by transferring atomized droplets of HMF to conc. $\mathrm{H}_{2} \mathrm{SO}_{4}$, subjecting the reactive system to successive treatment with diethyl ether, and a final heat treatment. The microporous humin derived from $\mathrm{HMF}$ at $400{ }^{\circ} \mathrm{C}$ (MHH-4) displayed higher specific surface area and pore volume than

Received: June 7, 2018

Accepted: July 20, 2018

Published: August 1, 2018 
that prepared at $200{ }^{\circ} \mathrm{C} \mathrm{MHH}-2$, as can be seen from Table 1 . These differences appear to relate to heat-induced removal of

Table 1. Textural Properties of MHH-2 and MHH-4 ${ }^{a}$

$\begin{array}{cccccc}\text { sample } & \begin{array}{c}S_{\mathrm{BET}} \\ \left(\mathrm{m}^{2} / \mathrm{g}\right)\end{array} & \begin{array}{c}S_{\mathrm{EXT}} \\ \left(\mathrm{m}^{2} / \mathrm{g}\right)\end{array} & \begin{array}{c}S_{\text {mic }} \\ \left(\mathrm{m}^{2} / \mathrm{g}\right)\end{array} & \begin{array}{c}V_{\mathrm{t}} \\ \left(\mathrm{cm}^{3} / \mathrm{g}\right)\end{array} & \begin{array}{c}V_{\text {mic }} \\ \left(\mathrm{cm}^{3} / \mathrm{g}\right)\end{array} \\ \text { MHH-2 } & 542 & 83 & 459 & 0.35 & 0.19 \\ \text { MHH-4 } & 1019 & 174 & 845 & 0.73 & 0.35\end{array}$

${ }^{a} \mathrm{MHH}-2$ and MHH-4 denote sorbents derived from HMF at 200 and $400{ }^{\circ} \mathrm{C}$, respectively. $S_{\mathrm{BET}}, S_{\mathrm{EXT}}$, and $S_{\text {mic }}$ are the BET-specific, external, and micropore surface areas, respectively. $V_{\mathrm{t}}$ and $V_{\text {mic }}$ denote total pore and micropore volumes, respectively.

small molecules. The yield for MHH-4 (40 wt \%) was lower than that for MHH-2 (56 wt \%). An additional valuable aspect of the procedure to synthesize the microporous humins was the high level of reproducibility. The corresponding $\mathrm{CO}_{2}$ sorption isotherms for replicates of $\mathrm{MHH}-4$ and $\mathrm{MHH}-2$ are displayed in Figures S1 and S2.

The heat treatment was important for the microporosity as was the other steps of the procedure. Treatment or washing with a solvent is commonly used but seldom discussed and can be considered crucial for the extraction of molecules, for example, solvents, catalysts, monomers, dimers, and so forth, from an already formed polymer or polymer precursor. ${ }^{19,20}$ However, diethyl ether appears not only to have extracted small molecules but also to have induced a phase separation which produced part of the solid phase of interest.

Molecular Analyses Revealed Largely Aromatic Structures. Conc. $\mathrm{H}_{2} \mathrm{SO}_{4}$ is an established oxidation and dehydration agent; ${ }^{18}$ however, the position of $\mathrm{MHH}-2$ in the van Krevelen diagram ${ }^{21}$ of Figure 1 shows that it is not a direct

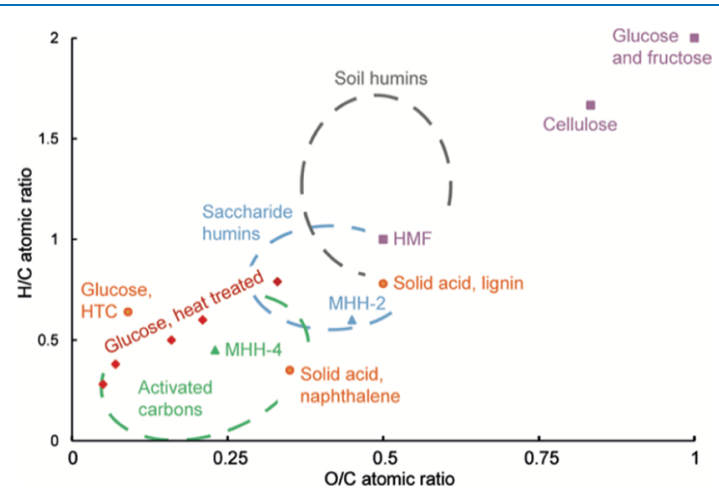

Figure 1. van Krevelen diagram showing microporous humins derived from HMF, saccharide and soil humins, solid acids, HTC of glucose, pyrolysis of glucose, and pure glucose, fructose, cellulose, and HMF (see Table S1). MHH-X denotes microporous humins derived from $\mathrm{HMF}$ at 200 and $400{ }^{\circ} \mathrm{C}$.

dehydration product $^{21-23}$ of HMF and HMF itself is a dehydration product of fructose/glucose. ${ }^{24}$ With the approximate chemical formula of $\mathrm{C}_{232} \mathrm{H}_{141} \mathrm{O}_{105} \mathrm{~S}, \mathrm{MHH}-2$ appeared instead to be a dehydrogenated ${ }^{25}$ product of HMF having a reduced $\mathrm{H} / \mathrm{C}$ ratio. This ratio was consistent with a (partly) aromatic structure. Even though the $\mathrm{O} / \mathrm{C}$ ratio of $\mathrm{MHH}-2$ was slightly smaller than that of HMF, it does not conclusively exclude that oxidation processes had occurred. ${ }^{26}$ A combination of dehydration and dehydrogenation processes could also lead to a reduced $\mathrm{O} / \mathrm{C}$ ratio. In comparison, solid acids derived from lignin ${ }^{27}$ showed higher $\mathrm{H} / \mathrm{C}$ and $\mathrm{O} / \mathrm{C}$ ratios than $\mathrm{MHH}$ -
2 , whereas a solid acid produced from naphthalene ${ }^{28}$ displayed a lower ratio. Hydrochars from glucose ${ }^{29}$ and humins, ${ }^{12,30}$ on the other hand, displayed lower $\mathrm{O} / \mathrm{C}$ ratios than $\mathrm{MHH}-2$. The carbon content of MHH-2 was higher than those in the solid acids produced from lignin ${ }^{27}$ and naphthalene ${ }^{28}$ but lower than those in the hydrochars derived from lapsi seeds and glucose. $^{29,31}$ The carbon content in MHH-2 compared well with humins but the hydrogen content was lower, except for the product from $\mathrm{HMF}$ heated to $190^{\circ} \mathrm{C}$ at $\mathrm{pH} 2.5$ (see Table S1), which had comparable values for both carbon and hydrogen contents. Furthermore, 0.69 wt \% of sulfur was introduced into $\mathrm{MHH}-2$. This amount was much smaller than that in many other solid acids, which have been shown to contain $3.9-20.0$ wt $\%$ of sulfur. ${ }^{27-29}$ Carbonaceous solids with sulfonic acid-based surface groups, known as sulfonated carbons, are heterogeneous solid acid catalysts. They are typically synthesized by direct and incomplete carbonization or postsynthetic modification of carbonized precursors with $\mathrm{H}_{2} \mathrm{SO}_{4}$ or other sulfonating agents. ${ }^{32,33}$

The approximate chemical formula of $\mathrm{MHH}-4$ was $\mathrm{C}_{470} \mathrm{H}_{213} \mathrm{O}_{109} \mathrm{~S}$ (Table S1). Its higher carbon content and lower $\mathrm{H} / \mathrm{C}$ and $\mathrm{O} / \mathrm{C}$ atomic ratios than those of $\mathrm{MHH}-2$ indicated a higher degree of aromatization. The carbon content was higher and the hydrogen content was lower than those in typical humins. ${ }^{34}$ Its position in the van Krevelen diagram ${ }^{21}$ of Figure 1 indicates that it was a dehydration product of HMF. A similar trend for the $\mathrm{H} / \mathrm{C}$ and $\mathrm{O} / \mathrm{C}$ atomic ratios, as for the HMF-to-MHH-4 transformation, has been observed for glucose treated with dilute $\mathrm{H}_{2} \mathrm{SO}_{4}$ and subjecting the formed material to a $\mathrm{CO}_{2}$ gas mixture and increasing the temperature. $^{35}$ In addition, MHH-4 contained even less sulfur than MHH-2 and had a similar oxygen-to-sulfur atomic ratio.

To study the molecular nature of the microporous humins, solid-state cross-polarization (CP) ${ }^{13} \mathrm{C}$ nuclear magnetic resonance (NMR) spectra were recorded for MHH-2. The spectrum in Figure 2 was recorded by using the total suppression of spinning sideband (TOSS) pulse sequence. ${ }^{36,37}$ It has broad bands centered at chemical shifts of 128,153 , and $189 \mathrm{ppm}$. These chemical shifts were assigned to the $\mathrm{sp}^{2}$ carbons of aromatic rings, linked $-\mathrm{HC}=\underline{\mathrm{C}}-\mathrm{O}$ in furanic rings or phenols, and carbonyls, respectively. No bands are observed at chemical shifts of $110-118 \mathrm{ppm}$, corresponding to $\mathrm{C}=\underline{\mathrm{C}}-$

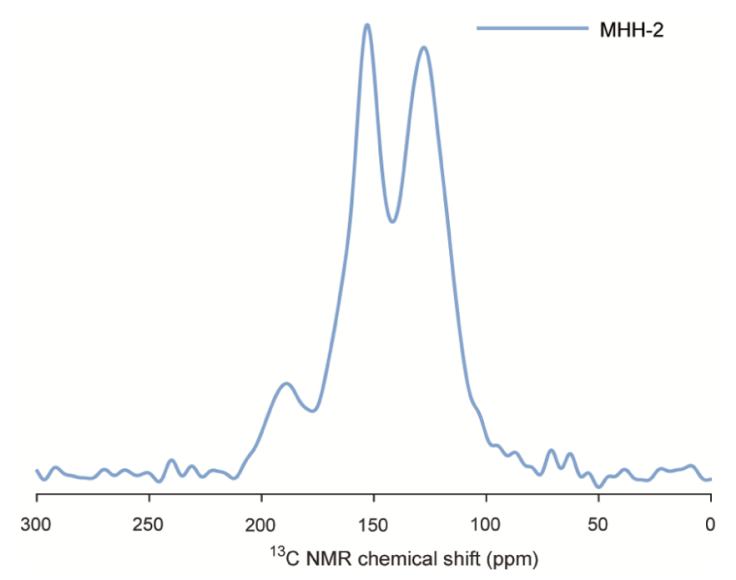

Figure 2. Solid-state cross-polarization ${ }^{13} \mathrm{C}$ nuclear magnetic resonance spectrum of $\mathrm{MHH}-2$ recorded under magic angle spinning with the total suppression of spinning sideband sequence. MHH-2 denotes microporous humin derived from HMF at $200{ }^{\circ} \mathrm{C}$. 
$\mathrm{C}$ or $\mathrm{O}-\mathrm{C}=\mathrm{CH}-$ in furanic rings. ${ }^{38,39}$ Also, the chemical shifts typical for aliphatic ${ }^{13} \mathrm{C}$ are absent, showing that this synthetic procedure was efficient in removing aliphatic carbon typically found in other humins. ${ }^{30,39}$ Consistent with the low sulfur content, the typical bands for sulfonated aromatics at chemical shifts of about $140 \mathrm{ppm}^{40,41}$ are not observed in Figure 2. Taken all together, the ${ }^{13} \mathrm{C} N \mathrm{NMR}$ data indicated that $\mathrm{MHH}-2$ was mainly aromatic with oxygen heteroatoms and carbonyl functional groups, likely aldehydes or carboxylic acids, and contained no detectable amounts of aliphatic carbons.

Analyses of the vibrational spectra of $\mathrm{MHH}-2$ and $\mathrm{MHH}-4$ allowed us to identify certain chemical groups and to recognize features of the disordered molecular nature. The Fourier transform infrared (FTIR) spectrum of $\mathrm{MHH}-2$ (Figure S4) has bands at frequencies of 1600 and $1716 \mathrm{~cm}^{-1}$, indicative of $\mathrm{C}=\mathrm{C}$ and $\mathrm{C}=\mathrm{O}$ bonds, respectively. ${ }^{42}$ The spectrum of $\mathrm{MHH}-4$ have larger relative absorbance of these bands, which are consistent with a larger fraction of aromatic $\mathrm{C}=\mathrm{C}$ bonds to $\mathrm{C}=\mathrm{O}$ bonds in $\mathrm{MHH}-4$ than that in $\mathrm{MHH}-2$. The Raman spectra in Figures S5-S8 show typical disordered carbon structures of the bands; ${ }^{43}$ however, they varied significantly with the laser power used. Changes occurred in the spectra already at a low laser power of $0.056 \mathrm{~mW}$ for the $532 \mathrm{~nm}$ laser. Less significant changes were observed in the spectra when using a $785 \mathrm{~nm}$ laser. For sample $\mathrm{MHH}-4$, no visible alteration of the spot on the sample that had been irradiated with laser light was observed. The damaging effects of laser irradiation on carbon materials are generally well established. ${ }^{44,45}$

Thermally Stable and Amorphous Structures. The microporous humins displayed relatively high thermal stability in an oxidizing atmosphere. The thermal gravimetric analysis (TGA) traces in Figure S9 were consistent with high stabilities of $\mathrm{MHH}-2$ and $\mathrm{MHH}-4$ up to temperatures of almost $300{ }^{\circ} \mathrm{C}$ in air. Certainly, the thermal stabilities were lower than those of typical activated carbons, ${ }^{15,46}$ but compared well with the solid acid produced from naphthalene. ${ }^{28}$ No ash content was detected after TGA.

As expected, the microporous humins had an amorphous nature as could be deduced from X-ray scattering analysis. The wide-angle X-ray scattering (WAXS) curves for MHH-2 and MHH-4 in Figure 3 are similar with broad peaks centered at $42^{\circ}$ and $21^{\circ}(2 \theta)$, respectively. The shoulder peak centered at $10^{\circ}$ is slightly more pronounced for MHH-4 than that for MHH-2. The peaks correspond to $q=2.9,1.5$, and $0.7 \AA^{-1}$. Various analyses of WAXS curves of carbon-rich amorphous solids, including those performed with reverse Monte Carlo routines, ${ }^{47,48}$ are consistent with $\mathrm{sp}^{2}$-hybridized structures. The

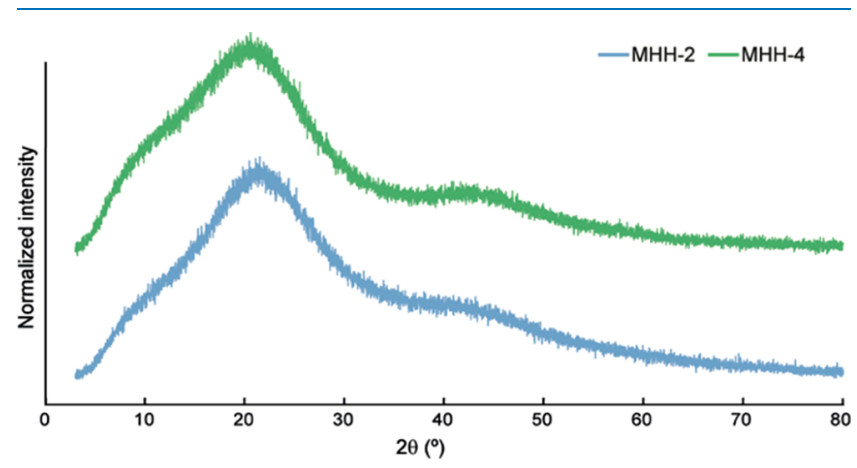

Figure 3. WAXS curves of microporous humins derived from HMF at 200 and $400{ }^{\circ} \mathrm{C}$ (MHH-X). relatively low signal-to-noise ratios of the WAXS data, recorded on an in-house diffractometer, limited the options for quantitative comparisons. Furthermore, the measurements were carried out under ambient conditions and water adsorption is known ${ }^{49}$ to shift the peaks to slightly higher $q$ values for activated carbons. Irrespectively, a qualitative discussion of the WAXS curves in Figure 3 is presented below.

The broad peaks and absence of sharp X-ray diffraction peaks $^{50}$ in the WAXS curves of MHH-2 and MHH-4 show that they are X-ray amorphous. Disordered aromatic carbon-rich structures are likely responsible for the broad peaks at $\sim 21$ and $\sim 42^{\circ}(2 \theta)$. For other and possibly related materials, this broadness has been discussed ${ }^{51}$ and attributed to, for instance, distorted graphitic structures ${ }^{52}$ and carbonaceous structures with differing degrees of crystallinity. ${ }^{50}$ Furthermore, the peaks centered at $21^{\circ}$ have also been attributed to aliphatic structures in coal, ${ }^{53}$ which is inconsistent with our findings from ${ }^{13} \mathrm{C}$ NMR analysis (Figure 2). They have also been attributed to disorder in $\mathrm{sp}^{2}$ carbons ${ }^{54}$ and to stacked aromatic layers with perpendicular crystallites. ${ }^{55}$ The shoulder centered at $10^{\circ}(2 \theta)$ or $q=0.7 \AA^{-1}$ is, to the best of our knowledge, not usually discussed for porous aromatic carbonaceous solids such as activated carbons. A peak in that position can result from oxygen functional groups in (and water between) aromatic carbon layers, ${ }^{56}$ which is typical for graphite oxide and consistent with our findings from elemental analysis and FTIR and ${ }^{13} \mathrm{C}$ NMR spectroscopy. Furthermore, amorphous solids, similar to graphite oxide and more or less reduced graphite oxide, can exhibit WAXS peaks at similar positions $(2 \theta \approx 10$, 21 , and $42^{\circ}$ ) as observed for MHH-2 and MHH-4. ${ }^{57-61}$

Textural Properties Derived from Gas Adsorption/ Desorption and Scanning Electron Microscopy. As mentioned, MHH-4 was more porous than MHH-2, cf. Table 1, and the corresponding $\mathrm{N}_{2}$ sorption isotherms in Figure 4 show large and steep uptake of $\mathrm{N}_{2}$ at low relative

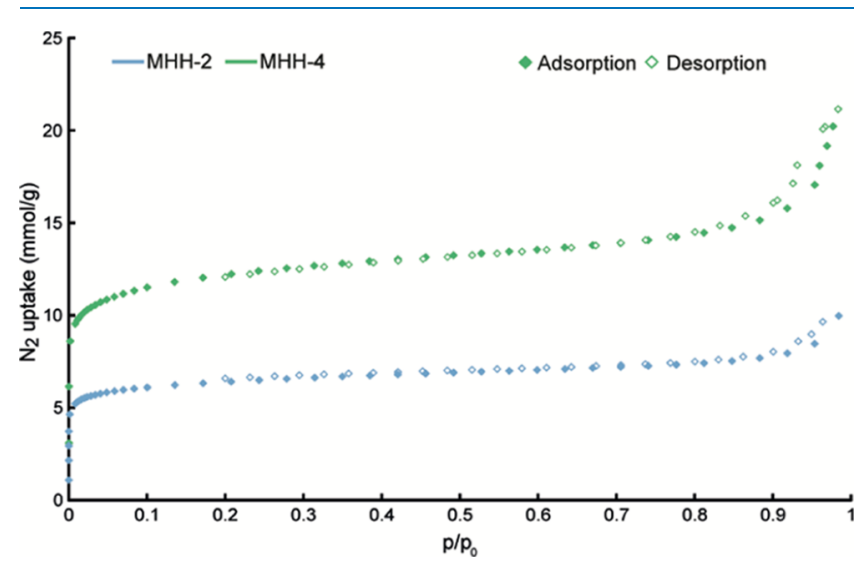

Figure 4. $\mathrm{N}_{2}$ uptake at $-196{ }^{\circ} \mathrm{C}$ on microporous humins derived from $\mathrm{HMF}$ at 200 and $400{ }^{\circ} \mathrm{C}$ (MHH-X).

pressures $\left(p / p_{0}\right)$, which is typical for micropores. ${ }^{62}$ They also display an almost linear region of adsorption of $\mathrm{N}_{2}$ at intermediate levels of $p / p_{0}$ and an increased adsorption as $p /$ $p_{0}$ approaches 1 . The adsorption of $\mathrm{N}_{2}$ does not reach a plateau for increasingly high values of $p / p_{0}$, which indicates that MHH-2 and MHH-4 contained macropores or consisted of small particles. ${ }^{62,63}$ The $\mathrm{N}_{2}$ adsorption/desorption isotherms in Figure 4 show slight hysteresis at $p / p_{0}$ of $0.8-1$ for both $\mathrm{MHH}-2$ and $\mathrm{MHH}-4$. Hysteresis is typically related to 
adsorption metastability, capillary condensation, network effects, swelling, pore blocking, and the shapes of the pores. ${ }^{62,64}$ In relation to these $\mathrm{N}_{2}$ adsorption isotherms, pore size distributions and cumulative pore volumes were calculated using a density functional theory (DFT) method. These are presented in Figures S10 and S11. To estimate the volume of small pores, the Dubinin-Radushkevich (DR) method was used to determine the ultramicropore volumes, using $\mathrm{CO}_{2}$ sorption data recorded at $0{ }^{\circ} \mathrm{C}$. MHH-4 and $\mathrm{MHH}-2$ had ultramicropore volumes of 0.39 and $0.25 \mathrm{~cm}^{3} / \mathrm{g}$ (see Figure S12 and Supporting calculations), respectively. As was expected, the ultramicropore volumes failed to fully agree with the micropore volumes (as was determined with the $t$-plot method using $\mathrm{N}_{2}$ adsorption data). $\mathrm{CO}_{2}$ is effectively smaller than $\mathrm{N}_{2}$ within sorbents, and the models and the pressure ranges used were different.

The microporous humins consisted of aggregated and interconnected particles with characteristic sizes of 10-100 $\mathrm{nm}$ as can be seen from the scanning electron microscopy (SEM) images in Figures 5, S13, and S14. Cavities and

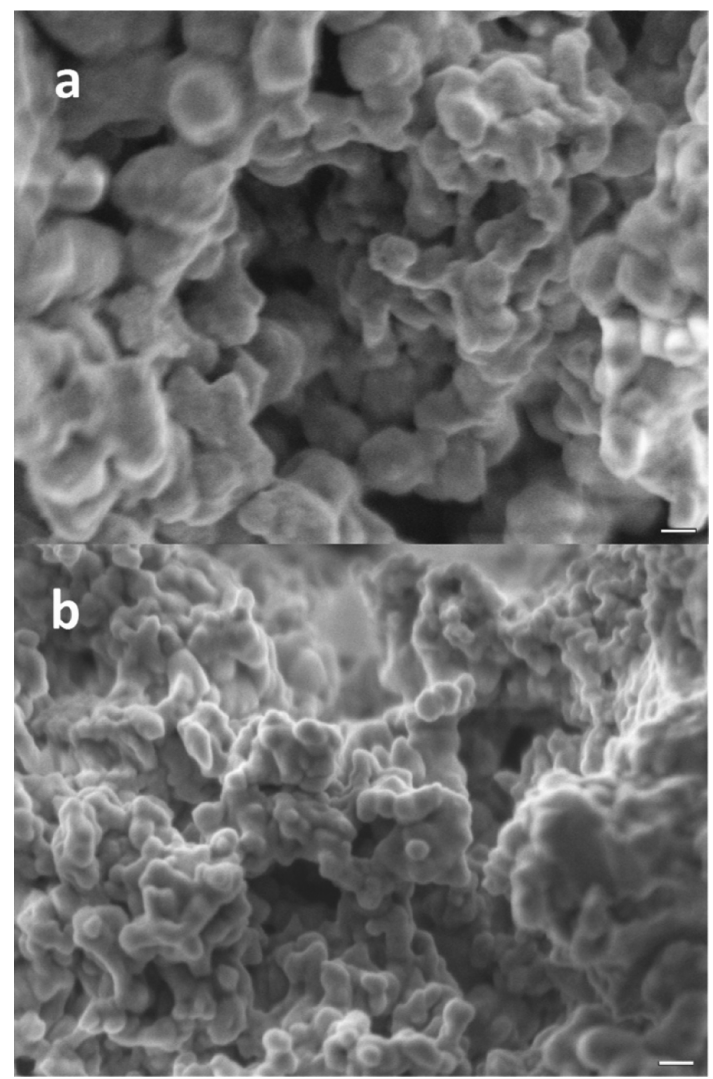

Figure 5. SEM images at $60000 \times$ magnification of microporous humins derived from HMF at (a) 200 and (b) $400{ }^{\circ} \mathrm{C}$ (MHH-X). The scale bars at the bottom right of each image correspond to 100 $\mathrm{nm}$.

channels had formed among the aggregated particles, and the interconnections appeared broadly distributed with respect to size and shape. The particle sizes were significantly smaller than the droplet size of the atomized HMF. Tentatively, the small sizes of the particles were assigned to features of the phase separation induced by the addition of diethyl ether. Carbon-rich solids, produced in different manners, such as carbon-coated counter electrodes, ${ }^{65}$ fuel cell cathodes, ${ }^{66}$ graphene oxide composites, ${ }^{67}$ carbon black, ${ }^{68}$ silicon carbide, ${ }^{69}$ and soot, ${ }^{54}$ have been shown to have comparable morphologies to those seen for $\mathrm{MHH}-2$ and $\mathrm{MHH}-4$. Such small and interconnected particles can, speculatively, enhance the mass transport rates important to various applications. Note that the SEM analyses of MHH-2 and MHH-4 showed charging, which is indicative of low conductivities. ${ }^{70,71}$

Gas Uptake and Selectivity. Compared with porous polymers (Table $S 3^{72-82}$ ), $\mathrm{MHH}-4$ showed the highest reported uptakes of $\mathrm{CO}_{2}$ at $0.15 \mathrm{bar}$ and $0{ }^{\circ} \mathrm{C}(2.18 \mathrm{mmol} /$ g), as shown in Figure 6. This low-pressure uptake was also

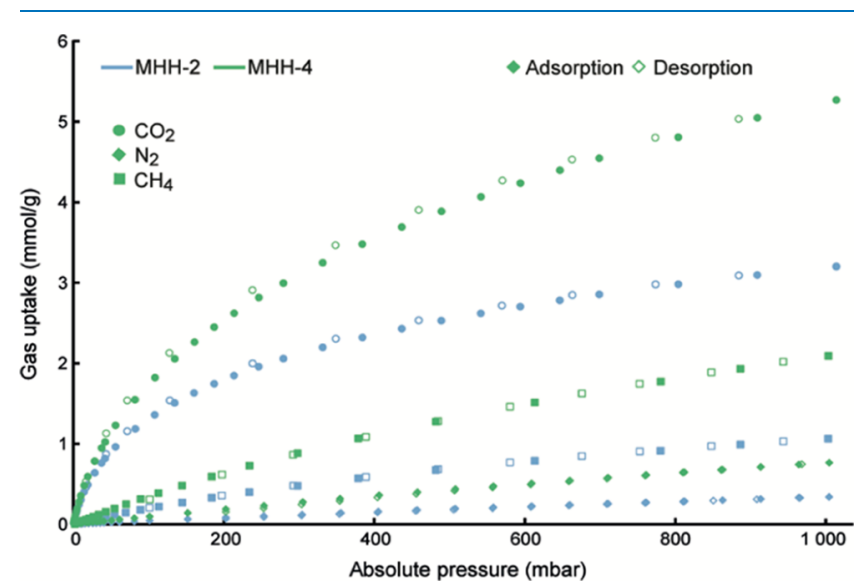

Figure 6. Sorption isotherms recorded at $0{ }^{\circ} \mathrm{C}$ for microporous humins derived from HMF at 200 and $400{ }^{\circ} \mathrm{C}$ (MHH-X).

comparable to some of the highest uptakes of activated carbons (Table S3). The $\mathrm{CO}_{2}$ uptake at 1 bar at $0{ }^{\circ} \mathrm{C}(5.27 \mathrm{mmol} / \mathrm{g})$ was on par with some of the best porous polymers but lower than those of certain activated carbons (Table S3), zeolites, and metal-organic frameworks. ${ }^{83,84}$ The uptake of $\mathrm{CH}_{4}$ was relatively high for $\mathrm{MHH}-4$, with a value of $2.09 \mathrm{mmol} / \mathrm{g}$ at 0 ${ }^{\circ} \mathrm{C}$ and 1 bar. For $\mathrm{MHH}-2$, the corresponding uptakes of $\mathrm{CO}_{2}$ and $\mathrm{CH}_{4}$ were somewhat lower, with values of 3.20 and 1.06 $\mathrm{mmol} / \mathrm{g}$ at $0{ }^{\circ} \mathrm{C}$ and $1 \mathrm{bar}$. The $\mathrm{CO}_{2}$ isotherms for $\mathrm{MHH}-2$ and $\mathrm{MHH}-4$ displayed slight hysteresis at intermediate pressures, which closed on high and low pressures of $\mathrm{CO}_{2}$. The uptakes of $\mathrm{N}_{2}$ at $0{ }^{\circ} \mathrm{C}$ and 1 bar were 0.34 and 0.77 $\mathrm{mmol} / \mathrm{g}$ for $\mathrm{MHH}-2$ and $\mathrm{MHH}-4$, respectively. The $\mathrm{CO}_{2}$ and $\mathrm{N}_{2}$ sorption isotherms recorded at $50{ }^{\circ} \mathrm{C}$ are shown in Figure S15.

Adsorption-driven capture of $\mathrm{CO}_{2}$ could potentially be less expensive than scrubbing technologies for $\mathrm{CO}_{2}$ capture and is hence researched for potential implementation. ${ }^{79}$ To evaluate the prospects of such capture, it is important to measure or estimate the binary adsorption of $\mathrm{CO}_{2}$ from gas mixtures. As it is time consuming and experimentally difficult to measure binary adsorption isotherms, various methods have been developed to estimate the binary adsorption from the singlecomponent adsorption data. The ideal adsorption solution theory (IAST) $)^{85}$ is one of the well-established methods.

The binary selectivites were estimated for the microporous humins with the IAST method, and the $\mathrm{CO}_{2}$-over- $\mathrm{N}_{2}$ selectivities in Figure $7 \mathrm{a}$ at $0{ }^{\circ} \mathrm{C}$ are higher for $\mathrm{MHH}-4$ than that for $\mathrm{MHH}-2$. At $p_{\text {tot }}=1 \mathrm{bar}$, the selectivity increased from 37 up to 65 for MHH-4 on increasing $y_{\mathrm{CO}_{2}}$. At $p_{\text {tot }}=0.1 \mathrm{bar}$, the selectivity stayed largely independent of $y_{\mathrm{CO}_{2}}$. We refrain from speculating whether this difference is explained by 

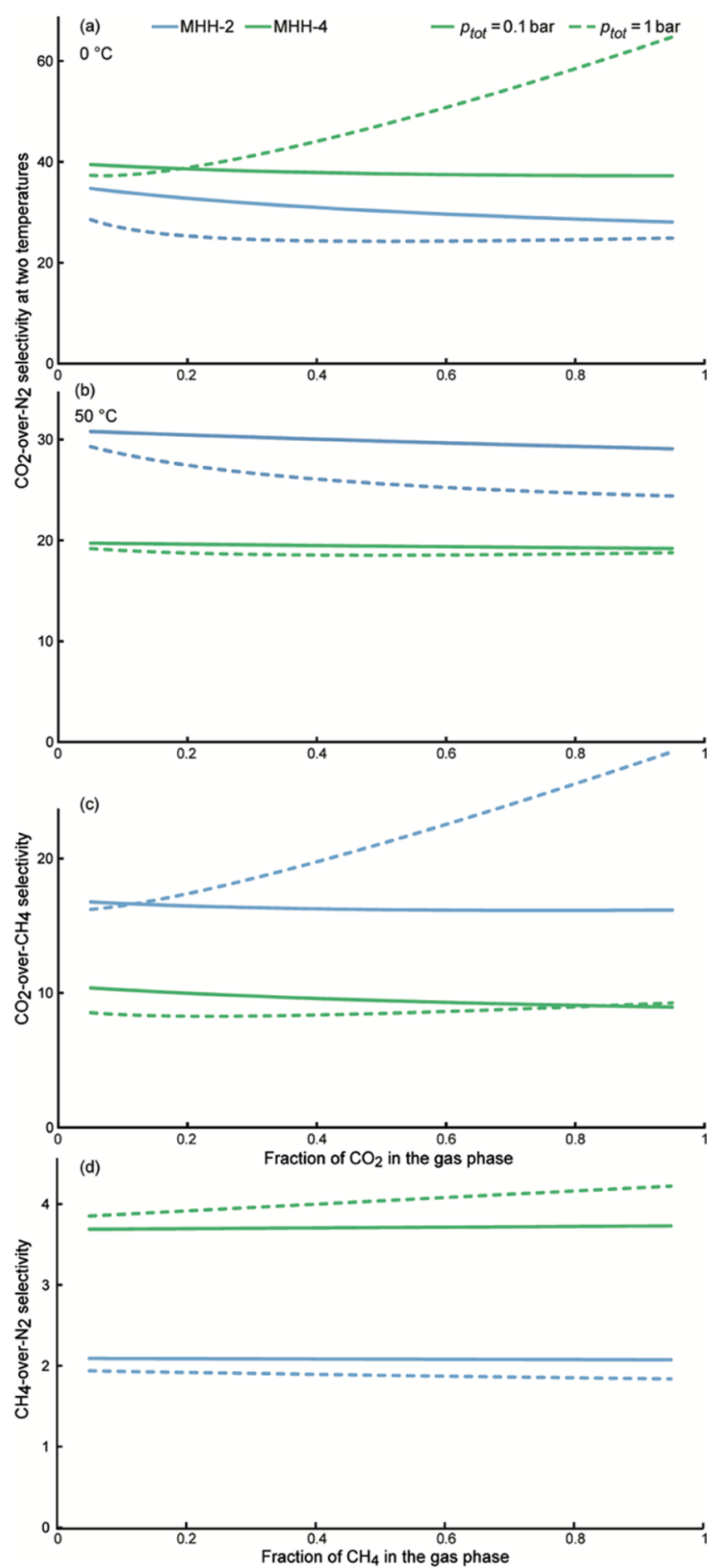

Figure 7. (a,b) $\mathrm{CO}_{2}$-over- $\mathrm{N}_{2}$ selectivity at 0 and $50{ }^{\circ} \mathrm{C}$, (c) $\mathrm{CO}_{2}$-over$\mathrm{CH}_{4}$ selectivity, and (d) $\mathrm{CH}_{4}$-over- $\mathrm{N}_{2}$ selectivity at $0{ }^{\circ} \mathrm{C}$. IAST was used. $\mathrm{MHH}-\mathrm{X}$ denotes microporous humins derived from HMF at 200 or $400{ }^{\circ} \mathrm{C}$.

physical reasons or if it is related to the mechanics of the IAST method. IAST has several limitations. These include assumptions of ideal mixing and that the adsorptive uptake of the least interactive gas needs to be integrated over quite a large pressure range, when the selectivity is high. Often, the high-pressure uptake of the least interacting gas is not measured, and hence, regression models are applied to predict the high-pressure adsorption data. Such regression analyses and integrations were performed for the IAST selectivities of this study. Consequently, the binary selectivities presented in Figure 7 at $p_{\text {tot }}=1$ bar are less robust than those of 0.1 bar. In contrast to the order observed at a temperature of $0{ }^{\circ} \mathrm{C}$, the selectivity was higher for $\mathrm{MHH}-2$ than that for $\mathrm{MHH}-4$ at a temperature of $50{ }^{\circ} \mathrm{C}$. At $p_{\text {tot }}=1$ bar and $y_{\mathrm{CO}_{2}}=0.15$ (relevant for postcombustion capture of $\mathrm{CO}_{2}{ }^{83}$ ), the selectivity was $\sim 19$ for MHH-4 (see Figure 7b). MHH-2, on the other hand, had for these $p-T-y_{\mathrm{CO}_{2}}$ conditions a selectivity of $\sim 28$. The selectivities for $\mathrm{MHH}-2$ and $\mathrm{MHH}-4$ were higher than those for most activated carbons. Related values for the $\mathrm{CO}_{2}$-over- $\mathrm{N}_{2}$ selectivity for other sorbents have been discussed elsewhere $79,82,86,87$ and are presented in Table S3.

Upgraded biogas has the potential to be amongst the most sustainable vehicle fuels ${ }^{88,89}$ if the waste biomass and the involved processes are selected with care. The main operation of the upgrading is to remove significant amounts of $\mathrm{CO}_{2}$. Such $\mathrm{CO}_{2}$ removal can be performed by, for example, adsorption-driven separation processes. ${ }^{88}$ Important properties of the involved sorbents include the $\mathrm{CO}_{2}$-over- $\mathrm{CH}_{4}$ selectivity. Hence, the IAST selectivity was calculated from $\mathrm{CO}_{2}$ and $\mathrm{CH}_{4}$ adsorption data and presented in Figure $7 \mathrm{c}$ as a function of $y_{\mathrm{CO}_{2}}$ at $p_{\text {tot }}=0.1$ and 1 bar. The selectivity for MHH-4 was $\sim 10$, whereas MHH-2 had higher values of 16-28. In the context of the upgrading of biogas (and landfill gas), $y_{\mathrm{CH}_{4}}$ is typically between 35 and $70 \%$ and $y_{\mathrm{CO}_{2}}$ is between 15 and $40 \% .{ }^{90}$ The reported selectivities of $\mathrm{MHH}-2$ and $\mathrm{MHH}-4$ were larger than those for regular activated carbons but smaller than those of certain carbon molecular sieves and zeolites. The $\mathrm{CO}_{2}$-over- $\mathrm{CH}_{4}$ selectivities for other adsorbents have been reviewed or presented elsewhere. ${ }^{91-93}$

The $\mathrm{CH}_{4}$-over- $\mathrm{N}_{2}$ selectivity metric is relevant in the context of adsorption-driven upgrading of landfill gas and natural gas, and selectivities for other sorbents have been presented elsewhere. $^{93,94}$ This metric was calculated for MHH-2 and MHH- 4 by using IAST and $\mathrm{CH}_{4}$ and $\mathrm{N}_{2}$ adsorption data and is presented in Figure $7 \mathrm{~d}$. The $\mathrm{CH}_{4}$-over- $\mathrm{N}_{2}$ selectivity was between 3.8 and 4.2 for MHH-4 and around 2 for MHH-2. See the Supporting Information for further details.

The isosteric heat of the sorption of $\mathrm{CO}_{2}\left(Q_{\mathrm{st}}\right)$ is important to adsorption-driven separation of $\mathrm{CO}_{2}$ from gas mixtures. A high $Q_{s t}$ value gives a high $\mathrm{CO}_{2}$ selectivity. A high $Q_{s t}$ value is related to a strong intermolecular interaction of $\mathrm{CO}_{2}$ with the electrical field gradients (EFGs) of these internal surfaces of the sorbent. Hence, $Q_{s t}$ of $\mathrm{CO}_{2}$ is connected to the pore size as well as the functional groups on the surface. ${ }^{95,96}$ However, a high value of $Q_{s t}$ also increases the regeneration cost of the sorbent. ${ }^{97}$ Hence, for adsorption-driven $\mathrm{CO}_{2}$ capture from flue gas mixtures, calculations have indicated that $Q_{\mathrm{st}}$ of $40-60 \mathrm{~kJ} /$ mol could be optimal but other theoretical work has shown vague relationships between $Q_{s t}$ and the cost of $\mathrm{CO}_{2}$ capture operations. ${ }^{98-100}$ The loading-dependent $Q_{s t}$ values for $\mathrm{MHH}$ 2 and $\mathrm{MHH}-4$ were determined with differential methods using temperature- and pressure-dependent $\mathrm{CO}_{2}$ sorption data and are presented in Figure 8. For MHH-4, $Q_{s t}$ was $42-44 \mathrm{~kJ} /$ mol, which is significantly higher than those typical for microporous polymers and activated carbons, ${ }^{78,95,96,101}$ as presented in Table S3. $Q_{s t}$ of MHH-2 was, on the other hand, typical for such sorbents with a value of $30-34 \mathrm{~kJ} / \mathrm{mol}$. The loading dependencies were weak. $Q_{\text {st }}$ increased slightly for $\mathrm{MHH}-4$ and decreased for $\mathrm{MHH}-2$ with increased loadings. 


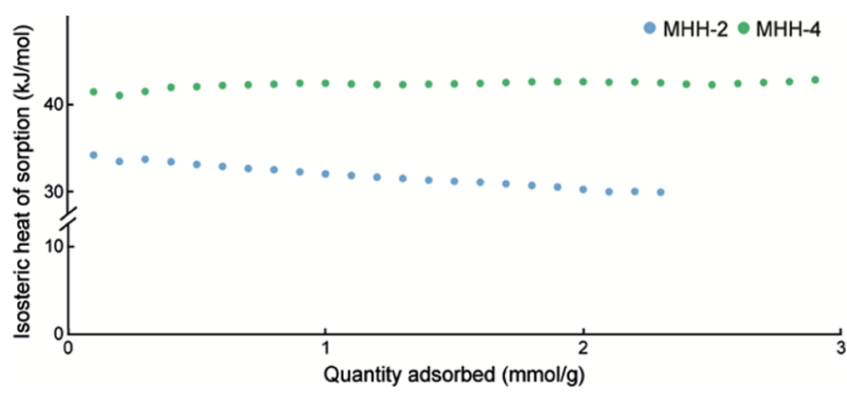

Figure 8. Isosteric heat of sorption of $\mathrm{CO}_{2}$ for microporous humins derived from HMF at 200 and $400{ }^{\circ} \mathrm{C}$ (MHH-X).

This weak dependency indicated a narrow distribution of EFGs, which is consistent with a low heterogeneity of the surface structure. ${ }^{102,103}$ The high $Q_{s t}$ values for MHH-4 likely result from narrow pores and, to some extent, carbonyl functional groups. (See Supporting Information for calculations and Figures S16-S19 for $\mathrm{CO}_{2}$ isotherms determined at different temperatures and the corresponding isosteres).

\section{CONCLUSIONS}

A new class of highly porous organic sorbents, called microporous humins, was synthesized with a new approach. Tiny droplets of HMF were added rapidly to conc. $\mathrm{H}_{2} \mathrm{SO}_{4}$ and the formed solids were subsequently treated with diethyl ether and heat. The microporous humins had high $Q_{\text {st }}$ values for sorption of $\mathrm{CO}_{2}$, large Brunauer-Emmett-Teller (BET) surface areas, and micropore volumes. The $\mathrm{CO}_{2}$-over- $\mathrm{N}_{2}$, $\mathrm{CO}_{2}$-over- $\mathrm{CH}_{4}$, and $\mathrm{CH}_{4}$-over- $\mathrm{N}_{2}$ selectivities were high and indicate potential usefulness of the sorbents in gas separation processes. High $Q_{\mathrm{st}}$ of sorption of $\mathrm{CO}_{2}$ for $\mathrm{MHH}-4$ could be relevant to further studies of this composition in relation to $\mathrm{CO}_{2}$ separation processes. The microporous humins contained aromatic structures with oxygen heteroatoms and carbonyl functional groups and no significant amounts of aliphatic groups. These structures were consistent with dehydration, dehydrogenation, and/or aromatization of HMF. The functional groups could be relevant to further surface modification. Only small amounts of sulfur were included in the sorbents and further studies on how to control the sulfur content or doping with other elements could be warranted. The impact of washing/extraction is seldom studied in the general class of porous polymers and it could be relevant to further studies on the synthesis of microporous humins. We also expect that other molecules than HMF could be polymerized in a similar manner and that the process methodologies could be further refined for upscale purposes. Currently, the cost of HMF is significant but new and improved processes are under the development. This together with the importance of HMF as a reaction intermediate and a potential platform chemical give a considerable potential to develop further the chemistry of HMF, both as a starting material (illustrated by this work) and with $\mathrm{HMF}$ as an intermediate.

\section{EXPERIMENTAL SECTION}

Synthesis of Sorbents from HMF. HMF ( $0.63 \mathrm{~g})$ was heated to $50{ }^{\circ} \mathrm{C}$ and subsequently atomized as tiny droplets (typically $30-100 \mu \mathrm{m}$ in size, according to the supplier of the device) and added to $10 \mathrm{~mL}$ of conc. $\mathrm{H}_{2} \mathrm{SO}_{4}$ under vigorous stirring at a temperature of $50{ }^{\circ} \mathrm{C}$. The mixture was kept under vigorous stirring at this temperature for $24 \mathrm{~h}$ and subsequently cooled down to room temperature. Diethyl ether was thereafter added carefully under stirring to a total volume of $50 \mathrm{~mL}$, while being cooled in a water bath. The resulting suspension was centrifuged, and the liquid phase was decanted. The procedure of adding diethyl ether and removing the liquid phase was repeated twice. The sorbents were dried in a flow of $\mathrm{N}_{2}$ and subsequently heated to temperatures of 200 or $400{ }^{\circ} \mathrm{C}$, also in a flow of $\mathrm{N}_{2}$. The yields were calculated by dividing the solid mass after heat treatment by the initial mass of HMF. All reagents were of a high-purity grade and used as supplied, unless otherwise stated.

Characterization. For elemental analysis, combustion analysis was used, and the samples were assumed to consist entirely of $\mathrm{C}, \mathrm{H}, \mathrm{N}, \mathrm{O}$, and $\mathrm{S}$. The mass of $\mathrm{O}$ was calculated by subtraction.

Solid-state $\mathrm{CP}{ }^{13} \mathrm{C}$ NMR spectra of $\mathrm{MHH}-2$ (Figures 2 and S3) were recorded under conditions of magic angle spinning (MAS) using the TOSS sequence. A Bruker AVANCE III spectrometer operating at a frequency of $400 \mathrm{MHz}$ for a frequency of $100.6 \mathrm{MHz}$ for ${ }^{13} \mathrm{C}$ was used and a $7 \mathrm{~mm}$ probe head was used. The MAS rate was $7 \mathrm{kHz}$, and the contributions from ${ }^{1} \mathrm{H}$ magnetization were lessened by decoupling with $50 \mathrm{kHz}$ during the acquisition of the ${ }^{13} \mathrm{C}$ signals. Ramped CP for $1.6 \mathrm{~ms}$ was used to transfer magnetization to ${ }^{13} \mathrm{C}$ from ${ }^{1} \mathrm{H}$.

A Varian 670-IR spectrometer with a Specac Goldengate attenuated total reflection device was used to record the FTIR spectra. It was equipped with a room-temperature deuterated triglycine sulfate detector.

Raman spectra were recorded with a HORIBA LabRAM HR 800 Raman spectrometer equipped with a double-frequency neodymium-doped yttrium-aluminum-garnet laser (532 nm/ $50 \mathrm{~mW}$ ) and an intracavity-regulated laser diode with point source $(785 \mathrm{~nm} / 100 \mathrm{~mW})$. The intensity of the lasers was adjusted by using a software-controlled filter wheel with six neutral density filters.

A PerkinElmer TGA 7 device was used for TGA in a flow of dry air. Approximately $3 \mathrm{mg}$ of the sample in a platinum cup was placed inside of the instrument and the weight was allowed to stabilize. Thereafter, the temperature was raised by $1{ }^{\circ} \mathrm{C} /$ min, from $27-900{ }^{\circ} \mathrm{C}$, and the weight was recorded.

A PANalytical X'Pert alphal powder diffractometer was used to record WAXS data from $2 \theta=3.0^{\circ}-80^{\circ}$ in a reflection mode with a PIXcel detector ( $\mathrm{Cu} \mathrm{K} \alpha 1$ radiation, $k=1.5406 \AA)$. The $q$-values were calculated according to $q=(4 \pi / k) \sin (2 \theta / 2)$.

SEM images were recorded using a JEOL JSM-7401F microscope equipped with an in-lens secondary-electron column detector. A "gentle beam" mode was used with a negative bias $(-2 \mathrm{kV})$ applied on the sample stage and a column accelerating voltage of $3 \mathrm{kV}$, generating a landing energy corresponding to $1 \mathrm{kV}$. The powders were fixated by using an ink. A working distance of $1.5 \mathrm{~mm}$ was used.

Adsorption and desorption isotherms were measured in an absolute pressure range of $0-101 \mathrm{kPa}$ using a Micromeritics ASAP 2020 device. Prior to sorption measurements, the samples were degassed at a temperature of 200 or $400{ }^{\circ} \mathrm{C}$ under conditions of dynamic vacuum for $6 \mathrm{~h} \mathrm{~N} \mathrm{~N}_{2}$ sorption isotherms were measured at temperatures of $-196,0$, and 50 ${ }^{\circ} \mathrm{C} . \mathrm{CO}_{2}$ sorption isotherms were measured at temperatures of $0,10,20$, and $50{ }^{\circ} \mathrm{C} . \mathrm{CH}_{4}$ sorption isotherms were measured at a temperature of $0{ }^{\circ} \mathrm{C}$. The $\mathrm{BET}^{104}$ model was used to calculate the specific surface areas $\left(S_{\mathrm{BET}}\right)$ using the lowtemperature $\left(-196{ }^{\circ} \mathrm{C}\right) \mathrm{N}_{2}$ uptake at $p / p_{0}$ values of $0-0.084$ 
for MHH-4 and 0-0.06 for MHH-2. The selected pressure range assured that $n\left(1-p / p_{0}\right)$ increased with $p / p_{0}$ and that the BET parameter $c$ was positive. The $t$-plot method (for carbon black and $\left.p / p_{0}=0.2-0.5\right)$ was used to determine $S_{\text {ext }}$ and $V_{\text {mic }} S_{\text {mic }}$ was calculated as the difference between $S_{\mathrm{BET}}$ and $S_{\text {ext }}{ }^{105,106} V_{\mathrm{t}}$ was determined at $p / p_{0}=0.98$. Details regarding the calculations can be found in the Supporting Information. A DFT-based method, supplied by Micromeritics routines, was used to estimate pore size distributions using the $\mathrm{N}_{2}$ adsorption data recorded at a temperature of $-196{ }^{\circ} \mathrm{C}$. The ultramicropore volumes were determined using the DR method and $\mathrm{CO}_{2}$ adsorption data at a temperature of $0{ }^{\circ} \mathrm{C}$, see Supporting Information for details. The IAST was used to calculate binary selectivity from single-component adsorption data, see the Supporting Information for details. $\mathrm{CO}_{2}$ sorption isotherms were recorded at a temperature of $0{ }^{\circ} \mathrm{C}$ on Micromeritics Gemini VII to verify the reproducibility of the synthesis.

\section{ASSOCIATED CONTENT}

\section{(S) Supporting Information}

The Supporting Information is available free of charge on the ACS Publications website at DOI: 10.1021/acsomega.8b01274.

Sorption isotherms; NMR, FTIR, and Raman spectra; TGA curves; DFT-calculated pore volumes and sizes; DR plot, SEM images, sorption isosters; $t$-plots; elemental compositions; gas uptake and apparent selectivities; $\mathrm{CO}_{2}$ uptake, selectivity, and heat of adsorption comparison; IAST data; heat of sorption; and calculations of $t$-plot, BET, total pore volume, IAST, heat of sorption, and DR micropore volume (PDF)

\section{AUTHOR INFORMATION}

\section{Corresponding Author}

*E-mail: niklas.hedin@mmk.su.se (N.H.).

\section{ORCID}

Diana Bernin: 0000-0002-9611-2263

Niklas Hedin: 0000-0002-7284-2974

\section{Present Address}

${ }^{\dagger}$ Department of Chemistry and Chemical Engineering, Chalmers University of Technology, SE-41296 Gothenburg, Sweden.

\section{Notes}

The authors declare the following competing financial interest(s): $\mathrm{NH}$ co-funded SIA NeoZeo that is commercializing biogas upgrading

\section{ACKNOWLEDGMENTS}

The authors acknowledge the support of the Swedish Energy Agency, VR (grant number 2016-03568), and VINNOVA and VR through the Berzelii Center EXSELENT on Porous Materials.

\section{REFERENCES}

(1) Dolores, L.-C.; Juan, P. M.-L.; Falco, C.; Titirici, M.-M.; Diego, C.-A. Sustainable Carbon Materials from Hydrothermal Processes; John Wiley \& Sons: Oxford, 2013.

(2) Titirici, M.-M.; White, R. J.; Brun, N.; Budarin, V. L.; Su, D. S.; del Monte, F.; Clark, J. H.; MacLachlan, M. J. Sustainable Carbon Materials. Chem. Soc. Rev. 2015, 44, 250-290.
(3) White, R. J.; Budarin, V.; Luque, R.; Clark, J. H.; Macquarrie, D. J. Tuneable Porous Carbonaceous Materials from Renewable Resources. Chem. Soc. Rev. 2009, 38, 3401-3418.

(4) Girisuta, B.; Janssen, L. P. B. M.; Heeres, H. J. A Kinetic Study on the Decomposition of 5-Hydroxymethylfurfural into Levulinic Acid. Green Chem. 2006, 8, 701.

(5) Esposito, D.; Antonietti, M. Redefining Biorefinery: The Search for Unconventional Building Blocks for Materials. Chem. Soc. Rev. 2015, 44, 5821-5835.

(6) Teong, S. P.; Yi, G.; Zhang, Y. Hydroxymethylfurfural Production from Bioresources: Past, Present and Future. Green Chem. 2014, 16, 2015.

(7) Climent, M. J.; Corma, A.; Iborra, S. Conversion of Biomass Platform Molecules into Fuel Additives and Liquid Hydrocarbon Fuels. Green Chem. 2014, 16, 516-547.

(8) van Putten, R.-J.; van der Waal, J. C.; de Jong, E.; Rasrendra, C. B.; Heeres, H. J.; de Vries, J. G. Hydroxymethylfurfural, a Versatile Platform Chemical Made from Renewable Resources. Chem. Rev. 2013, 113, 1499-1597.

(9) Titirici, M.-M.; Antonietti, M. Chemistry and Materials Options of Sustainable Carbon Materials Made by Hydrothermal Carbonization. Chem. Soc. Rev. 2010, 39, 103-116.

(10) Mija, A.; van der Waal, J. C.; van Klink, G.; de Jong, E. HuminsContaining Foam. WO 2017/074183 A1, 2016.

(11) Love, R. M. Spectroscopic studies of carbohydrates. 1. The action of sulphuric acid on sugars. Biochem. J. 1953, 55, 126-132.

(12) Sumerskii, I. V.; Krutov, S. M.; Zarubin, M. Y. Humin-like Substances Formed under the Conditions of Industrial Hydrolysis of Wood. Russ. J. Appl. Chem. 2010, 83, 320-327.

(13) Dias, J. M.; Alvim-Ferraz, M. C. M.; Almeida, M. F.; RiveraUtrilla, J.; Sánchez-Polo, M. Waste Materials for Activated Carbon Preparation and Its Use in Aqueous-Phase Treatment: A Review. J. Environ. Manage. 2007, 85, 833-846.

(14) Kim, D.-Y.; Nishiyama, Y.; Wada, M.; Kuga, S. High-Yield Carbonization of Cellulose by Sulfuric Acid Impregnation. Cellulose 2001, 8, 29-33.

(15) Ryoo, R.; Joo, S. H.; Jun, S. Synthesis of Highly Ordered Carbon Molecular Sieves via Template-Mediated Structural Transformation. J. Phys. Chem. B 1999, 103, 7743-7746.

(16) Zhou, Z.; Zhao, X. S.; Zeng, X. T. Surface Patterning with Carbon Thin Films by Nanosphere Lithography. Surf. Coat. Technol. 2005, 198, 178-183.

(17) Alatalo, S.-M.; Pileidis, F.; Mäkilä, E.; Sevilla, M.; Repo, E.; Salonen, J.; Sillanpää, M.; Titirici, M.-M. Versatile Cellulose-Based Carbon Aerogel for the Removal of Both Cationic and Anionic Metal Contaminants from Water. ACS Appl. Mater. Interfaces 2015, 7, 25875-25883.

(18) Hu, Y.; Yang, J.; Tian, J.; Jia, L.; Yu, J.-S. Waste Frying Oil as a Precursor for One-Step Synthesis of Sulfur-Doped Carbon Dots with PH-Sensitive Photoluminescence. Carbon 2014, 77, 775-782.

(19) Rabbani, M. G.; El-Kaderi, H. M. Synthesis and Characterization of Porous Benzimidazole-Linked Polymers and Their Performance in Small Gas Storage and Selective Uptake. Chem. Mater. 2012, 24, 1511-1517.

(20) Xu, Y.; Jin, S.; Xu, H.; Nagai, A.; Jiang, D. Conjugated Microporous Polymers: Design, Synthesis and Application. Chem. Soc. Rev. 2013, 42, 8012-8031.

(21) Van Krevelen, D. W. Graphical Statistical Method for the Study of Structure and Reaction Processes of Coal. Fuel 1950, 29, 269-284.

(22) Sevilla, M.; Fuertes, A. B. The Production of Carbon Materials by Hydrothermal Carbonization of Cellulose. Carbon 2009, 47, 2281-2289.

(23) Sevilla, M.; Fuertes, A. B. Chemical and Structural Properties of Carbonaceous Products Obtained by Hydrothermal Carbonization of Saccharides. Chem.-Eur. J. 2009, 15, 4195-4203.

(24) Rosatella, A. A.; Simeonov, S. P.; Frade, R. F. M.; Afonso, C. A. M. 5-Hydroxymethylfurfural (HMF) as a Building Block Platform: Biological Properties, Synthesis and Synthetic Applications. Green Chem. 2011, 13, 754. 
(25) Klavins, M.; Purmalis, O. Genesis of Peat Humic Acid Structure and Properties Within Bog Profile. Functions of Natural Organic Matter in Changing Environment; Xu, J., Wu, J., He, Y., Eds.; Springer Netherlands: Dordrecht, 2013; pp 101-105.

(26) Kroll, J. H.; Donahue, N. M.; Jimenez, J. L.; Kessler, S. H.; Canagaratna, M. R.; Wilson, K. R.; Altieri, K. E.; Mazzoleni, L. R.; Wozniak, A. S.; Bluhm, H.; et al. Carbon oxidation state as a metric for describing the chemistry of atmospheric organic aerosol. Nat. Chem. 2011, 3, 133-139.

(27) Guo, F.; Xiu, Z.-L.; Liang, Z.-X. Synthesis of Biodiesel from Acidified Soybean Soapstock Using a Lignin-Derived Carbonaceous Catalyst. Appl. Energy 2012, 98, 47-52.

(28) Hara, M.; Yoshida, T.; Takagaki, A.; Takata, T.; Kondo, J. N.; Hayashi, S.; Domen, K. A Carbon Material as a Strong Protonic Acid. Angew. Chem., Int. Ed. 2004, 43, 2955-2958.

(29) Liang, X.; Yang, J. Synthesis of a Novel Carbon Based Strong Acid Catalyst through Hydrothermal Carbonization. Catal. Lett. 2009, 132, 460-463.

(30) Van Zandvoort, I.; Wang, Y.; Rasrendra, C. B.; Van Eck, E. R. H.; Bruijnincx, P. C. A.; Heeres, H. J.; Weckhuysen, B. M. Formation, Molecular Structure, and Morphology of Humins in Biomass Conversion: Influence of Feedstock and Processing Conditions. ChemSusChem 2013, 6, 1745-1758.

(31) Shrestha, R. M.; Varga, I.; Bajtai, J.; Varga, M. Design of Surface Functionalization of Waste Material Originated Charcoals by an Optimized Chemical Carbonization for the Purpose of Heavy Metal Removal from Industrial Waste Waters. Microchem. J. 2013, 108, 224-232.

(32) Kang, S.; Ye, J.; Chang, J. Recent Advances in Carbon-Based Sulfonated Catalyst: Preparation and Application. Int. Rev. Chem. Eng. 2013, 5, 133-144.

(33) Nakajima, K.; Hara, M. Amorphous Carbon with $\mathrm{SO} 3 \mathrm{H}$ Groups as a Solid Brønsted Acid Catalyst. ACS Catal. 2012, 2, $1296-$ 1304.

(34) Girisuta, B.; Janssen, L. P. B. M.; Heeres, H. J. Kinetic Study on the Acid-Catalyzed Hydrolysis of Cellulose to Levulinic Acid. Ind. Eng. Chem. Res. 2007, 46, 1696-1708.

(35) Hoang, T. M. C.; van Eck, E. R. H.; Bula, W. P.; Gardeniers, J. G. E.; Lefferts, L.; Seshan, K. Humin Based By-Products from Biomass Processing as a Potential Carbonaceous Source for Synthesis Gas Production. Green Chem. 2015, 17, 959-972.

(36) Dixon, W. T. Spinning-sideband-free and spinning-sidebandonly NMR spectra in spinning samples. J. Chem. Phys. 1982, 77, 1800-1809.

(37) Dixon, W. T.; Schaefer, J.; Sefcik, M. D.; Stejskal, E. O.; McKay, R. A. Total Suppression of Sidebands in CPMAS C-13 NMR. J. Magn. Reson. 1982, 49, 341-345.

(38) Falco, C.; Baccile, N.; Titirici, M.-M. Morphological and Structural Differences between Glucose, Cellulose and Lignocellulosic Biomass Derived Hydrothermal Carbons. Green Chem. 2011, 13, 3273.

(39) van Zandvoort, I.; Koers, E. J.; Weingarth, M.; Bruijnincx, P. C. A.; Baldus, M.; Weckhuysen, B. M. Structural characterization of 13Cenriched humins and alkali-treated $13 \mathrm{C}$ humins by $2 \mathrm{D}$ solid-state NMR. Green Chem. 2015, 17, 4383-4392.

(40) Moujahid, E. M.; Inacio, J.; Besse, J.-P.; Leroux, F. Adsorption of Styrene Sulfonate vs. Polystyrene Sulfonate on Layered Double Hydroxides. Microporous Mesoporous Mater. 2003, 57, 37-46.

(41) Nakajima, K.; Tomita, I.; Hara, M.; Hayashi, S.; Domen, K.; Kondo, J. N. A Stable and Highly Active Hybrid Mesoporous Solid Acid Catalyst. Adv. Mater. 2005, 17, 1839-1842.

(42) Sun, X.; Li, Y. Colloidal Carbon Spheres and Their Core/Shell Structures with Noble-Metal Nanoparticles. Angew. Chem., Int. Ed. 2004, 43, 597-601.

(43) Merlen, A.; Buijnsters, J.; Pardanaud, C. A Guide to and Review of the Use of Multiwavelength Raman Spectroscopy for Characterizing Defective Aromatic Carbon Solids: From Graphene to Amorphous Carbons. Coatings 2017, 7, 153.
(44) Ferrari, A. C.; Robertson, J. Resonant Raman Spectroscopy of Disordered, Amorphous, and Diamondlike Carbon. Phys. Rev. B: Condens. Matter Mater. Phys. 2001, 64, 075414.

(45) Kundu, A.; Rani, R.; Hazra, K. S. Graphene Oxide Demonstrates Experimental Confirmation of Abraham Pressure on Solid Surface. Sci. Rep. 2017, 7, 42538.

(46) Rychlicki, G.; Terzyk, A. P.; Majchrzycki, W. The Effect of Commercial Carbon De-Ashing on Its Thermal Stability and Porosity. J. Chem. Technol. Biotechnol. 1999, 74, 329-336.

(47) Jain, S. K.; Pellenq, R. J.-M.; Gubbins, K. E. Structural Modeling of Porous Carbons Using a Hybrid Reverse Monte Carlo Method. Adsorption 2007, 3, 129-137.

(48) Jain, S. K.; Pellenq, R. J.-M.; Pikunic, J. P.; Gubbins, K. E. Molecular Modeling of Porous Carbons Using the Hybrid Reverse Monte Carlo Method. Langmuir 2006, 22, 9942-9948.

(49) László, K.; Czakkel, O.; Dobos, G.; Lodewyckx, P.; Rochas, C.; Geissler, E. Water Vapour Adsorption in Highly Porous Carbons as Seen by Small and Wide Angle X-Ray Scattering. Carbon 2010, 48, 1038-1048.

(50) Omri, A.; Benzina, M.; Ammar, N. Preparation, Modification and Industrial Application of Activated Carbon from Almond Shell. J. Ind. Eng. Chem. 2013, 19, 2092-2099.

(51) Marsh, H.; Rodríguez-Reinoso, F. Activated Carbon; Elsevier: Amsterdam, 2006.

(52) Pechyen, C.; Atong, D.; Aht-Ong, D.; Sricharoenchaikul, V. Investigation of Pyrolyzed Chars from Physic Nut Waste for the Preparation of Activated Carbon. J. Solid Mech. Mater. Eng. 2007, 1, 498-507.

(53) Sonibare, O. O.; Haeger, T.; Foley, S. F. Structural Characterization of Nigerian Coals by X-Ray Diffraction, Raman and FTIR Spectroscopy. Energy 2010, 35, 5347-5353.

(54) Mohan, A. N.; Manoj, B. Synthesis and Characterization of Carbon Nanospheres from Hydrocarbon Soot. Int. J. Electrochem. Sci. 2012, 7, 9537-9549.

(55) Takagi, H.; Maruyama, K.; Yoshizawa, N.; Yamada, Y.; Sato, Y. XRD Analysis of Carbon Stacking Structure in Coal during Heat Treatment. Fuel 2004, 83, 2427-2433.

(56) Thakur, S.; Karak, N. Green Reduction of Graphene Oxide by Aqueous Phytoextracts. Carbon 2012, 50, 5331-5339.

(57) Park, S.; An, J.; Potts, J. R.; Velamakanni, A.; Murali, S.; Ruoff, R. S. Hydrazine-Reduction of Graphite- and Graphene Oxide. Carbon 2011, 49, 3019-3023.

(58) Blanton, T. N.; Majumdar, D. Characterization of X-Ray Irradiated Graphene Oxide Coatings Using X-Ray Diffraction, X-Ray Photoelectron Spectroscopy, and Atomic Force Microscopy. Powder Diffr. 2013, 28, 68-71.

(59) Blanton, T. N.; Majumdar, D. X-Ray Diffraction Characterization of Polymer Intercalated Graphite Oxide. Powder Diffr. 2012, 27, 104-107.

(60) Mu, S.-J.; Su, Y.-C.; Xiao, L.-H.; Liu, S.-D.; Hu, T.; Tang, H.-B. X-Ray Difraction Pattern of Graphite Oxide. Chin. Phys. Lett. 2013, 30, 096101.

(61) Loryuenyong, V.; Totepvimarn, K.; Eimburanapravat, P.; Boonchompoo, W.; Buasri, A. Preparation and Characterization of Reduced Graphene Oxide Sheets via Water-Based Exfoliation and Reduction Methods. Adv. Mater. Sci. Eng. 2013, 2013, 1-5.

(62) Thommes, M.; Kaneko, K.; Neimark, A. V.; Olivier, J. P.; Rodriguez-Reinoso, F.; Rouquerol, J.; Sing, K. S. W. Physisorption of Gases, with Special Reference to the Evaluation of Surface Area and Pore Size Distribution. Pure Appl. Chem. 2015, 87, 1051-1069.

(63) Leofanti, G.; Padovan, M.; Tozzola, G.; Venturelli, B. Surface Area and Pore Texture of Catalysts. Catal. Today 1998, 41, 207-219.

(64) Sing, K. The Use of Nitrogen Adsorption for the Characterisation of Porous Materials. Colloids Surf., A 2001, 187-188, 3-9.

(65) Murakami, T. N.; Ito, S.; Wang, Q.; Nazeeruddin, M. K.; Bessho, T.; Cesar, I.; Liska, P.; Humphry-Baker, R.; Comte, P.; Péchy, P.; et al. Highly Efficient Dye-Sensitized Solar Cells Based on Carbon Black Counter Electrodes. J. Electrochem. Soc. 2006, 153, A2255. 
(66) Liu, Z. Y.; Brady, B. K.; Carter, R. N.; Litteer, B.; Budinski, M.; Hyun, J. K.; Muller, D. A. Characterization of Carbon CorrosionInduced Structural Damage of PEM Fuel Cell Cathode Electrodes Caused by Local Fuel Starvation. J. Electrochem. Soc. 2008, 155, B979-B984.

(67) Silva, A. M. T.; Fonseca, N. N. C.; Vaz, J. R.; Figueiredo, J. L.; Faria, J. L. Photocatalytic Reduction of $\mathrm{CO} 2$ with Water into Methanol and Ethanol Using Graphene Derivative - TiO2 Composites: Effect of PH and Copper (I) Oxide. Top. Catal. 2016, 59, 1279-1291.

(68) Li, X.; Li, X.; Banis, M. N.; Wang, B.; Lushington, A.; Cui, X.; Li, R.; Sham, T.-K.; Sun, X. Tailoring interactions of carbon and sulfur in Li-S battery cathodes: significant effects of carbon-heteroatom bonds. J. Mater. Chem. A 2014, 2, 12866.

(69) van Laar, J. H.; van der Walt, I. J.; Bissett, H.; Puts, G. J.; Crouse, P. L. Synthesis and deposition of silicon carbide nanopowders in a microwave-induced plasma operating at low to atmospheric pressures. J. South. Afr. Inst. Min. Metall. 2015, 115, 949-955.

(70) Park, J. B.; Kim, Y.-J.; Yoo, J. M.; Kim, Y.; Kim, S. M.; Kim, S. J.; Gorbachev, R.; Barbolina, I. I.; Yoon, J. M.; Hee, B. H.; et al. NonDestructive Electron Microscopy Imaging and Analysis of Biological Samples with Graphene Coating. 2D Materials 2016, 3, 045004.

(71) Scipioni, R.; Jørgensen, P. S.; Ngo, D.-T.; Simonsen, S. B.; Liu, Z.; Yakal-Kremski, K. J.; Wang, H.; Hjelm, J.; Norby, P.; Barnett, S. A.; et al. Electron microscopy investigations of changes in morphology and conductivity of LiFePO $4 / \mathrm{C}$ electrodes. J. Power Sources 2016, 307, 259-269.

(72) Hao, W.; Björnerbäck, F.; Trushkina, Y.; Oregui Bengoechea, M.; Salazar-Alvarez, G.; Barth, T.; Hedin, N. High-Performance Magnetic Activated Carbon from Solid Waste from Lignin Conversion Processes. 1. Their Use As Adsorbents for CO2. ACS Sustainable Chem. Eng. 2017, 5, 3087-3095.

(73) Sevilla, M.; Falco, C.; Titirici, M.-M.; Fuertes, A. B. HighPerformance CO2 Sorbents from Algae. RSC Adv. 2012, 2, 12792.

(74) Wahby, A.; Ramos-Fernández, J. M.; Martínez-Escandell, M.; Sepúlveda-Escribano, A.; Silvestre-Albero, J.; Rodríguez-Reinoso, F. High-Surface-Area Carbon Molecular Sieves for Selective CO2 Adsorption. ChemSusChem 2010, 3, 974-981.

(75) Sevilla, M.; Fuertes, A. B. Sustainable porous carbons with a superior performance for $\mathrm{CO} 2$ capture. Energy Environ. Sci. 2011, 4, 1765.

(76) Creamer, A. E.; Gao, B. Carbon-Based Adsorbents for Postcombustion $\mathrm{CO} 2$ Capture: A Critical Review. Environ. Sci. Technol. 2016, 50, 7276-7289.

(77) Lee, S.-Y.; Park, S.-J. A Review on Solid Adsorbents for Carbon Dioxide Capture. J. Ind. Eng. Chem. 2015, 23, 1-11.

(78) Wang, W.; Zhou, M.; Yuan, D. Carbon Dioxide Capture in Amorphous Porous Organic Polymers. J. Mater. Chem. A 2017, 5, 1334-1347.

(79) Samanta, A.; Zhao, A.; Shimizu, G. K. H.; Sarkar, P.; Gupta, R. Post-Combustion CO2 Capture Using Solid Sorbents: A Review. Ind. Eng. Chem. Res. 2012, 51, 1438-1463.

(80) Deng, S.; Wei, H.; Chen, T.; Wang, B.; Huang, J.; Yu, G. Superior CO2 Adsorption on Pine Nut Shell-Derived Activated Carbons and the Effective Micropores at Different Temperatures. Chem. Eng. J. 2014, 253, 46-54.

(81) Alabadi, A.; Razzaque, S.; Yang, Y.; Chen, S.; Tan, B. Highly porous activated carbon materials from carbonized biomass with high CO 2 capturing capacity. Chem. Eng. J. 2015, 281, 606-612.

(82) Xu, C.; Hedin, N. Microporous adsorbents for CO2 capture - a case for microporous polymers? Mater. Today 2014, 17, 397-403.

(83) Sayari, A.; Belmabkhout, Y.; Serna-Guerrero, R. Flue Gas Treatment via CO2 Adsorption. Chem. Eng. J. 2011, 171, 760-774.

(84) Cheung, O.; Hedin, N. Zeolites and Related Sorbents with Narrow Pores for CO2 Separation from Flue Gas. RSC Adv. 2014, 4, 14480-14494.

(85) Myers, A. L.; Prausnitz, J. M. Thermodynamics of Mixed-Gas Adsorption. AIChE J. 1965, 11, 121-127.
(86) Yu, C.-H.; Huang, C.-H.; Tan, C.-S. A Review of CO2 Capture by Absorption and Adsorption. Aerosol Air Qual. Res. 2012, 12, 745769.

(87) Li, J.-R.; Ma, Y.; McCarthy, M. C.; Sculley, J.; Yu, J.; Jeong, H.K.; Balbuena, P. B.; Zhou, H.-C. Carbon Dioxide Capture-Related Gas Adsorption and Separation in Metal-Organic Frameworks. Coord. Chem. Rev. 2011, 255, 1791-1823.

(88) Grande, C. A. Biofuel's Engineering Process Technology; Dos Santos Bernardes, M. A., Ed.; InTech, 2011.

(89) Edwards, R.; Larive, J.-F.; Rickeard, D.; Weindorf, W. Well-toTank Version 4 JEC Well-to-Wheels Analysis, Luxembourg, 2013.

(90) Sun, Q.; Li, H.; Yan, J.; Liu, L.; Yu, Z.; Yu, X. Selection of Appropriate Biogas Upgrading Technology-a Review of Biogas Cleaning, Upgrading and Utilisation. Renewable Sustainable Energy Rev. 2015, 51, 521-532.

(91) Chaemchuen, S.; Kabir, N. A.; Zhou, K.; Verpoort, F. MetalOrganic Frameworks for Upgrading Biogas via $\mathrm{CO} 2$ Adsorption to Biogas Green Energy. Chem. Soc. Rev. 2013, 42, 9304-9332.

(92) Nugent, P.; Belmabkhout, Y.; Burd, S. D.; Cairns, A. J.; Luebke, R.; Forrest, K.; Pham, T.; Ma, S.; Space, B.; Wojtas, L.; et al. Porous Materials with Optimal Adsorption Thermodynamics and Kinetics for CO2 Separation. Nature 2013, 495, 80-84.

(93) Yuan, B.; Wu, X.; Chen, Y.; Huang, J.; Luo, H.; Deng, S. Adsorption of $\mathrm{CO} 2, \mathrm{CH} 4$, and $\mathrm{N} 2$ on Ordered Mesoporous Carbon: Approach for Greenhouse Gases Capture and Biogas Upgrading. Environ. Sci. Technol. 2013, 47, 5474-5480.

(94) Ren, X.; Sun, T.; Hu, J.; Wang, S. Highly Enhanced Selectivity for the Separation of $\mathrm{CH} 4$ over N2 on Two Ultra-Microporous Frameworks with Multiple Coordination Modes. Microporous Mesoporous Mater. 2014, 186, 137-145.

(95) Himeno, S.; Komatsu, T.; Fujita, S. High-Pressure Adsorption Equilibria of Methane and Carbon Dioxide on Several Activated Carbons. J. Chem. Eng. Data 2005, 50, 369-376.

(96) Dawson, R.; Adams, D. J.; Cooper, A. I. Chemical Tuning of CO2 Sorption in Robust Nanoporous Organic Polymers. Chem. Sci. 2011, 2, 1173.

(97) Dawson, R.; Stöckel, E.; Holst, J. R.; Adams, D. J.; Cooper, A. I. Microporous Organic Polymers for Carbon Dioxide Capture. Energy Environ. Sci. 2011, 4, 4239.

(98) Hasan, M. M. F.; First, E. L.; Floudas, C. A. Cost-Effective CO2 Capture Based on in Silico Screening of Zeolites and Process Optimization. Phys. Chem. Chem. Phys. 2013, 15, 17601.

(99) Lin, L.-C.; Berger, A. H.; Martin, R. L.; Kim, J.; Swisher, J. A.; Jariwala, K.; Rycroft, C. H.; Bhown, A. S.; Deem, M. W.; Haranczyk, M.; et al. In Silico Screening of Carbon-Capture Materials. Nat. Mater. 2012, 11, 633-641.

(100) Huck, J. M.; Lin, L.-C.; Berger, A. H.; Shahrak, M. N.; Martin, R. L.; Bhown, A. S.; Haranczyk, M.; Reuter, K.; Smit, B. Evaluating different classes of porous materials for carbon capture. Energy Environ. Sci. 2014, 7, 4132-4146.

(101) Lu, W.; Yuan, D.; Sculley, J.; Zhao, D.; Krishna, R.; Zhou, H.C. Sulfonate-Grafted Porous Polymer Networks for Preferential CO2Adsorption at Low Pressure. J. Am. Chem. Soc. 2011, 133, 18126-18129.

(102) Belmabkhout, Y.; Sayari, A. Effect of pore expansion and amine functionalization of mesoporous silica on $\mathrm{CO} 2$ adsorption over a wide range of conditions. Adsorption 2009, 15, 318-328.

(103) Rege, S. U.; Yang, R. T.; Buzanowski, M. A. Sorbents for Air Prepurification in Air Separation. Chem. Eng. Sci. 2000, 55, 48274838.

(104) Brunauer, S.; Emmett, P. H.; Teller, E. Adsorption of Gases in Multimolecular Layers. J. Am. Chem. Soc. 1938, 60, 309-319.

(105) Lowell, S.; Shields, J. E.; Thomas, M. A.; Thommes, M. Characterization of Porous Solids and Powders: Surface Area, Pore Size and Density; Springer, 2004; Vol. 16.

(106) ASTM International. Standard Test Method for Carbon Black-Total and External Surface Area by Nitrogen, 2012; Vol. D6556. 